\title{
REFLEXÕES SOBRE A PRÁTICA DOCENTE NO ENSINO DA ESCRITA/REESCRITA DA RESENHA DE FILMES
}

\author{
REFLECTIONS ON TEACHER PRACTICE IN THE TEACHING OF THE \\ WRITING / REPRINT OF THE FILM REVIEW
}

\author{
Paulo da Silva Lima ${ }^{1}$ \\ Luciana de Queiroz Lima
}

\begin{abstract}
Resumo: Este artigo aborda o uso de ferramentas didáticas no ensino do gênero textual Resenha. Para isso, são analisadas as ações de uma professora que utilizou a Sequência Didática como instrumento norteador de sua prática pedagógica durante sua pesquisa-ação do Mestrado Profissional em Letras. Objetiva analisar questões teóricas sobre o ensino de gêneros e a prática de sala de aula. Os resultados demonstram que, apesar de não ter se apropriado de alguns saberes teóricos sobre o ensino de gêneros, a professora busca contemplar em sua prática atividades que estimulem os alunos a efetivarem verdadeiras ações de linguagem nas aulas.
\end{abstract}

Palavras-chave: Gênero textual; Ensino; Sequência didática.

\begin{abstract}
This article discusses the use of didactic tools in teaching the textual genre Review. For this, the actions of a teacher who used the Didactic Sequence as the guiding instrument of her pedagogical practice during her action research of the Professional Master's Degree in Literature are analyzed. It aims to analyze theoretical questions about the teaching of gender and the practice of classroom. The results demonstrate that, despite not having appropriated some theoretical knowledge about gender teaching, the teacher seeks to contemplate in her practice activities that stimulate the students to carry out true actions of language in the classes.
\end{abstract}

Keywords: Textual genre; Teaching; Didactic sequence.

\section{Introdução}

No Ensino Fundamental, nas aulas de produção de texto, muitos professores se prendem somente à correção de "erros" ortográficos e morfossintáticos. Além disso, a atividade de

\footnotetext{
${ }^{1}$ Possui graduação em Letras pela Universidade Estadual do Maranhão (2002), mestrado em Letras pela Universidade Presbiteriana Mackenzie (2008) e doutorado em Letras (Estudos Linguísticos) pela Universidade Presbiteriana Mackenzie (2014). Tem Pós-doutorado em Linguística pela Universidade de Brasília (UNB). Atualmente é professor adjunto da Universidade Federal do Maranhão, Campus de Bacabal, atuando como coordenador de curso. É professor do Mestrado Acadêmico em Letras e do Mestrado Profissional em Letras da Universidade Federal do Sul e Sudeste do Pará (ProfLetras/Unifesspa). Tem experiência na área de Letras, com ênfase em Língua Portuguesa, atuando principalmente nos seguintes temas: ensino, discurso, leitura, argumentação e análise do discurso. E-mail: paulodasilvalima@ yahoo.com.br

${ }^{2}$ Professora da rede pública de ensino do Estado do Pará.
} 
produção textual raramente visa à interação, pois os textos, na maioria das vezes, são escritos apenas para servirem de base para o lançamento de conceitos ou notas.

Nessa perspectiva, o ensino pode ter outro viés. As atividades de escrita e reescrita de textos, na escola, devem ser direcionadas não só para apontar os "erros" dos alunos, mas também possibilitar um conjunto de atividades que englobem leitura, produção e análise linguística. Além disso, devem ter como finalidade estabelecer vínculos interativos, ou seja, os alunos devem desde cedo ser estimulados a escrever textos reais, com fins específicos, cientes de que para cada situação deverão adequar sua produção, seja ela oral ou escrita.

Neste artigo, buscamos fazer uma análise confrontando algumas questões teóricas com práticas reais de ensino de Língua Portuguesa no Ensino Fundamental, refletindo sobre as seguintes questões: a) O ensino organizado em sequências de atividades didáticas contribui para a prática docente? b) Como o professor elabora e aplica uma sequência de atividades didáticas de forma que contribua para o desenvolvimento das capacidades de linguagem e das práticas discursivas dos alunos?

Embasados em autores como Antunes (2009), Dolz e Schneuwly (2004), Dolz (2010), Marcuschi (2012), dentre outros, e seguindo uma abordagem interacionista da linguagem, procuramos, num primeiro momento deste artigo, discorrer sobre o ensino de gêneros textuais no Ensino Fundamental, demonstrando como se articula, nas secretarias municipais do Sul do Pará, a inserção dos gêneros textuais. No tópico seguinte, abordamos questões teóricas ligadas ao uso de ferramentas didáticas no ensino de gêneros e, por último, apresentamos um relato reflexivo de uma experiência com o ensino do gênero textual resenha de filme no $9^{\circ}$ ano do Ensino Fundamental.

\section{Gêneros de texto no Ensino Fundamental}

Os Parâmetros Curriculares Nacionais de Língua Portuguesa (PCNLP) do Ensino Fundamental (BRASIL, 2001; 1998) estabelecem que a escola deve oferecer condições para que os alunos desenvolvam seus conhecimentos sabendo: a) ler e escrever textos orais e escritos conforme seus propósitos e demandas sociais; b) expressar-se adequadamente em situações de interação oral diferentes daquelas próprias de seu universo imediato, ou seja, do convívio familiar; c) refletir sobre os fenômenos da linguagem, particularmente os que tocam a questão da variedade linguística, combatendo a estigmatização, discriminação e preconceitos relativos ao uso da língua. 
A dimensão interacional e discursiva da língua vem sendo discutida há muito tempo, pois os PCNLP (BRASIL, 2001, p.34) já reconheciam que os conteúdos de Língua Portuguesa deveriam ser articulados em torno do uso da língua oral e escrita e da reflexão acerca dos usos. E, para que isto ocorra, chegamos a uma conclusão que parece óbvia: precisamos redirecionar o ensino de línguas, a partir do texto, pois o falante se comunica através de textos, sejam eles falados ou escritos.

Para articularmos o ensino de Língua Portuguesa em torno dos dois grandes eixos sugeridos pelos PCNLP, uso e reflexão, o professor deve, então, partir de situações reais de utilização da língua, levando em consideração que o ensino deve partir do texto, pois, segundo Antunes (2007, p.130), "o texto é a forma prioritária de se usar a língua".

O trabalho com textos em sala de aula não deve acontecer também sem qualquer objetivo, como vem ocorrendo em muitas escolas, em que os alunos escrevem para serem avaliados ou somente para que o professor leia e corrija os "erros". Correção essa que, na maioria das vezes, não ultrapassa a "superfície" do texto. É preciso também acabar com o mito de que texto bom é aquele sem erros ortográficos.

Segundo Marcuschi (2012, p. 21-22), todo falante sabe intuitivamente distinguir um texto de um não texto, sabe que a produção linguística geralmente se dá em textos e não em palavras isoladas. Temos, então, que o falante se comunica através de textos e não de frases soltas, não importando se essa comunicação acontece através de textos extensos como nos livros, ou de textos curtos como em um bilhete.

Para Dolz (2010, p. 39), uma língua natural só é aprendida por meio de produções verbais efetivas, orais ou escritas, sendo que essas realizações empíricas diversas são chamadas de "texto". Sendo assim, é fácil concluir que os gêneros textuais são excelentes aliados para o ensino de línguas, uma vez que eles são a forma como esses "textos" (a língua) se organizam nas inúmeras situações interativas em que vivemos no dia a dia. Os gêneros textuais surgem, situam-se e integram-se funcionalmente nas culturas em que se desenvolvem, sendo caracterizados por suas funções comunicativas, cognitivas e institucionais. Sendo de difícil definição formal, os gêneros devem "ser contemplados em seus usos e condicionamentos sociopragmáticos caracterizados como práticas sociodiscursivas”. (MARCUSCHI,2010, p. 20)

Também é importante atentar para a distinção entre tipo textual e gênero textual, pois essa distinção pode orientar a ação do professor no trabalho com a compreensão e a produção textual, já que as sequências ou tipos textuais funcionam no interior dos gêneros. Partindo do 
pressuposto de que é impossível se comunicar verbalmente a não ser por algum texto e da ideia de que a comunicação verbal só é possível por algum gênero textual, em que a língua é tida como uma forma de ação social e histórica, Marcuschi(2010) apresenta uma breve definição das duas noções:

(a) Usamos a expressão tipo textual para designar uma espécie de sequência teoricamente definida pela natureza linguística de sua composição \{aspectos lexicais, sintáticos, tempos verbais, relações lógicas\}. Em geral, os tipos textuais abrangem cerca de meia dúzia de categorias conhecidas como: narração, argumentação, exposição, descrição, injunção.

(b) Usamos a expressão gênero textual como uma noção propositalmente vaga para referir os textos materializados que encontramos em nossa vida diária e que apresentam características sócio-comunicativas definidas por conteúdos, propriedades funcionais, estilo e composição característica. Se os tipos são apenas meia dúzia, os gêneros são inúmeros. (MARCUSCHI, 2010, p.23)

Gênero textual é, então, o nome dado às diferentes "formas verbais de ação social relativamente estáveis realizadas em textos" (MARCUSCHI, 2010, p. 26), que circulam socialmente, sendo, às vezes, mais formais ou mais informais. E, como língua em uso, são instrumentos de interação indispensáveis, pois todas as pessoas utilizam algum gênero para interagir verbalmente. Quanto mais gêneros textuais o falante dominar, mais acesso terá a uma participação efetiva em sociedade.

Destacamos, aqui, a relevância de se trabalhar no Ensino Fundamental, desde as séries iniciais, com os diferentes gêneros textuais, uma vez que eles são construtos sociais que orientam a atividade interativa de todos os seres humanos. Todos nós utilizamos e dominamos algum gênero, seja ele formal ou informal para expressarmos ideias, crenças, sentimentos etc. O gênero pode ser considerado como língua viva. Como os falantes já dominam algum tipo de gênero (oral e/ou escrito) fica mais fácil partir desses conhecimentos para ensinar/aprender outros gêneros.

Assim, mudanças no ensino são evidentes, necessárias e solicitadas há algum tempo. Cabe ao professor de Língua Portuguesa assumir o papel de pesquisador e redirecionador da própria prática para, de fato, efetivar um ensino relevante para a vida do aluno em sociedade.

\section{Uso de ferramentas didáticas no ensino de gêneros}


Segundo o PCNLP (BRASIL, 1998), existem dois modos de organização didática especiais para o ensino dos gêneros: os projetos e os módulos. A característica básica de um projeto é que ele tem um objetivo compartilhado por todos os envolvidos, que se expressa num produto final em função do qual todos trabalham e que terá, necessariamente, destinação e divulgação/circulação social internamente na escola ou fora dela. Já os módulos didáticos são sequências de atividades e exercícios que são organizados de forma gradual permitindo que os alunos, progressivamente, se apropriem das características discursivas e linguísticas dos gêneros estudados, ao produzir seu próprio texto.

Destacamos aqui que o trabalho com os módulos é muito interessante para a transposição didática dos gêneros textuais, uma vez que o planejamento dos módulos parte do diagnóstico das capacidades iniciais dos alunos, permitindo ao professor identificar quais instrumentos didáticos podem promover a aprendizagem e a superação dos problemas apresentados inicialmente pelos discentes.

No Brasil, a abordagem mais recorrente para o ensino de gêneros tem sido a fundamentada na tradição suíça, o Interacionismo Sociodiscursivo, baseada nas perspectivas bakhtinianas sobre a interação comunicativa e na teoria da aprendizagem e da atividade de Vygotsky. Essa abordagem se expandiu largamente no Brasil após publicação dos PCNLP, que adotam essa perspectiva de ensino.

Planejar um ensino de Língua Portuguesa seguindo a abordagem sociointeracionista requer compreender a língua como um articulador das relações cotidianas com os outros falantes, e seu ensino. Como já destacado, deve proporcionar aos alunos situações reais (social) de interação, as quais só acontecem mediadas por um gênero textual.

Assumindo a teoria apresentada e destacando-se a necessidade de o ensino de Língua Portuguesa ser orientado por uma metodologia que proporcione ao aluno a realização de atividades consistentes de leitura e produção textual, além da utilização de diferentes gêneros textuais, o trabalho com sequências de atividades didáticas pode trazer contribuições ao professor e a proposição de atividades com foco na forma e no funcionamento da linguagem, com ênfase na interação social.

Schneuwly e Dolz (2004), com base em um trabalho realizado nas instituições de ensino da Suíça, apresentam uma proposta para o ensino dos gêneros textuais, a "sequência didática" (SD), com intuito de permitir aos alunos apropriarem-se das noções, das técnicas e dos instrumentos necessários para que desenvolvam suas capacidades de expressão oral e escrita 
nas mais diversas situações de comunicação. Ao propor um ensino de gênero através da SD, os autores enfatizam que este procedimento, se bem direcionado pelos professores, possibilita o desenvolvimento das capacidades de produção textual (orais e escritas) dos alunos, em situações reais de interação.

Os autores definem SD como: "[...] um conjunto de atividades escolares organizadas, de maneira sistemática, em torno de um gênero" que "servem para dar acesso aos alunos a práticas de linguagem novas ou dificilmente domináveis" (SCHNEUWLY; DOLZ, 2004, p. 82-83). Esse procedimento tem como principal finalidade ajudar o aluno a dominar melhor um gênero de texto, permitindo-lhe falar ou escrever adequadamente nas diversas situações comunicacionais. Logo, esse trabalho tem que ser desenvolvido sobre os gêneros que os alunos ainda não dominam, dificilmente acessíveis pela maioria dos estudantes, e ainda sobre gêneros públicos ou privados.

A estrutura básica de uma SD foi representada esquematicamente pelos referidos autores da seguinte forma:

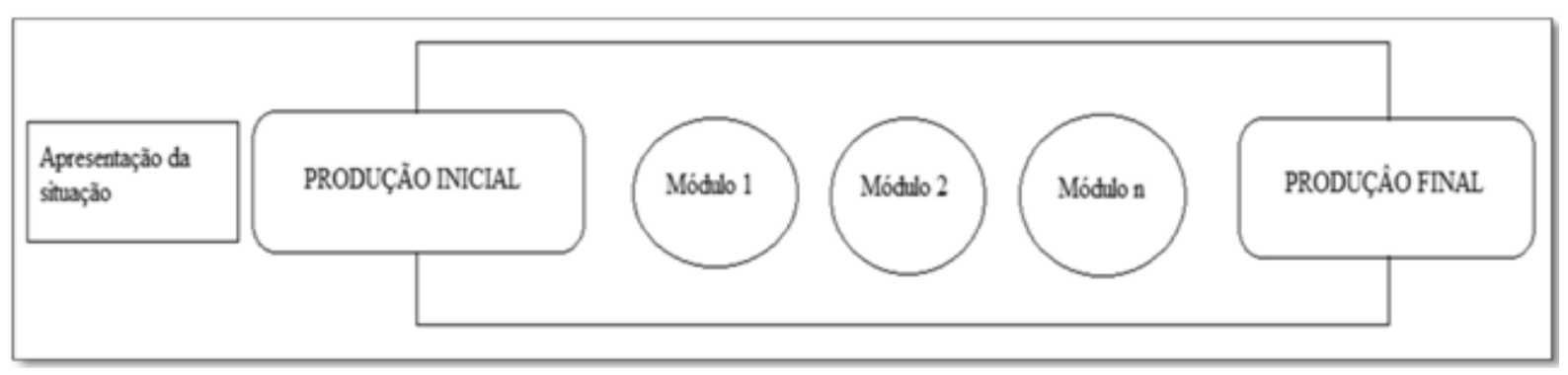

Observando a figura acima, notamos que o primeiro momento de uma SD é a apresentação da situação. Nesta fase, o professor deve descrever aos alunos, de forma detalhada, a situação de interação que será efetivada e por meio de qual gênero, ou seja, o docente deve descrever a produção oral ou escrita que os alunos deverão produzir. Nesse momento, devem ser fornecidas aos alunos todas as informações necessárias para que conheçam o projeto de interação visado.

Em seguida, no momento da produção inicial, os alunos tentam elaborar um primeiro texto, oral ou escrito. Ao solicitar essa produção, o professor deve ter por objetivo observar o que os alunos já sabem sobre o gênero solicitado. Esta etapa serve como um diagnóstico, no 
qual são observadas as dificuldades reveladas pelos discentes e, em seguida, são elaboradas as atividades que serão desenvolvidas nos módulos.

Uma análise das primeiras produções, segundo Schneuwly e Dolz (2004), permite avaliar em que ponto os alunos estão e quais são as dificuldades enfrentadas por eles. Assim, buscando uma "solução" para os problemas que tenham aparecido, surgem os módulos como instrumentos necessários para superá-los. Nessa etapa, é importante que o professor proponha atividades diversificadas.

Em geral, durante a aplicação de uma SD, pode-se registrar, em uma lista, tudo o que foi adquirido nos módulos. Essa lista pode ser construída ao longo do trabalho ou elaborada em um momento de síntese, antes da produção final, podendo ainda ser redigida pelos alunos ou proposta pelo professor. Assim, "independente das modalidades de elaboração cada sequência é finalizada com um registro dos conhecimentos adquiridos sobre o gênero durante o trabalho nos módulos, na forma sintética de lista de constatações". (SCHNEUWLY; DOLZ, 2004, p.90)

Por último, é solicitada aos alunos a elaboração de uma versão final do seu texto. Desse modo, o estudante tem a oportunidade de pôr em prática as noções e os instrumentos elaborados separadamente nos módulos. Além disso, é possível a realização de uma avaliação do tipo somativa, utilizando a lista de constatações ou outra grade como parâmetro para a avaliação. Esse tipo de avaliação abandona os critérios quase sempre gramaticais e muda o foco para a adequação à situação interativa para a qual o texto foi produzido.

É importante destacar que o ensino fica mais fácil a partir do momento em que seus objetivos são descritos e explicitados. Como os gêneros são identificados pelos seus usos e são nomeados e categorizados pelos seus falantes, trabalhar seu ensino a partir de representações sociais facilita sua aprendizagem. Dolz (2010, p. 47-50) destaca a necessidade de o professor construir um "modelo didático do gênero" a ser didatizado. A construção deste modelo envolve a identificação das dimensões ensináveis que podem gerar atividades e sequências de ensino. O modelo didático do gênero é uma ferramenta fundamental para organizar o ensino da produção textual.

O modelo didático é a descrição provisória das principais características de um gênero textual com o objetivo de ensiná-las. É uma construção em engenharia didática que explicita as seguintes dimensões: a) os saberes de referência a serem mobilizados para se trabalhar os gêneros; b) a descrição dos diferentes componentes textuais específicos; e c) as capacidades de linguagem do aluno. (DOLZ, 2010, p. 48) 
Segundo o autor, o modelo didático deve trazer um conjunto de recursos que podem ser transformados em conteúdos potenciais de ensino que serão mobilizados nas atividades escolares. Por possibilitar várias realizações, podemos considerá-lo como uma base de dados para a construção do conjunto de sequências de atividades didáticas.

Para Schneuwly e Dolz (2004), o modelo didático serve para explicitar o conhecimento do gênero que será ensinado. Para isso, primeiramente, é preciso, com base nas dimensões ensináveis do gênero a ser trabalhado, fazer um levantamento do conjunto de conhecimentos de cunho social, cognitivo e linguístico, que são acionados no momento em que se produz ou recebe um gênero de texto. Nesse caso, estamos nos referindo às capacidades de linguagem: "adaptar-se as características do contexto e do referente (capacidade de ação); mobilizar modelos discursivos (capacidade discursiva); dominar as operações psicolinguísticas e as unidades linguísticas (capacidade linguístico-discursiva)”. (SCHNEUWLY; DOLZ, 2004, p. 44)

Assim, a modelização do gênero auxilia nas ações dos professores em sala de aula, desde a elaboração das atividades a serem realizadas até o momento de correção e avaliação dos textos produzidos.

Segundo Machado e Cristovão (2006), é necessário destacar que a construção de um modelo didático de gênero não precisa ser perfeita, nem teoricamente pura. Para construí-lo, podemos reunir diversas referências teóricas, assim como referências originárias da observação e da análise das práticas sociais que envolvem o gênero a ser didatizado. Por fim, as próprias atividades que serão feitas nas aulas e que se centrarem nesse gênero permitiriam um retorno ao modelo didático, admitindo a sua consecutiva reelaboração.

Segundo Machado (2005), o modelo proposto para essas operações não pode ser visto como linear, pois as operações apresentadas não se sucedem umas às outras na ordem em que serão apresentadas e sim em uma interação continua.

Apresentamos a seguir um quadro, adaptado de Nascimento (2014), que mostra o modelo didático do gênero resenha de filme, modelo este que, na SD aplicada durante a pesquisa, poderia ter servido de base para a elaboração das atividades a serem trabalhadas nos módulos didáticos, assim como poderia auxiliar na construção da lista de constatações a ser utilizada na correção dos textos produzidos pelos alunos. 


\begin{tabular}{|c|c|c|}
\hline $\begin{array}{c}\text { Características da resenha } \\
\text { crítica }\end{array}$ & Descritores & $\begin{array}{l}\text { Objetivos específicos: os alunos } \\
\text { devem ser capazes de: }\end{array}$ \\
\hline $\begin{array}{l}\text { Capacidades de ação requeridas } \\
\text { para a prática } \\
\text { social: } \\
\text { SITUAÇÃO DE } \\
\text { COMUNICAÇÃO } \\
\text { E REFERENTE } \\
\text { TEMÁ- } \\
\text { TICO }\end{array}$ & $\begin{array}{l}\text { Gênero escrito, inicialmente } \\
\text { tido como pertencente à esfera } \\
\text { acadêmica; a resenha de filme } \\
\text { normalmente ligada à esfera } \\
\text { jornalística; } \\
\text { Normalmente publicado em } \\
\text { jornais, revistas e na internet; } \\
\text { Escrito por um crítico, } \\
\text { resenhista, em se tratando da } \\
\text { resenha de filme, pode ser } \\
\text { escrito por pessoas que gostam } \\
\text { de cinema; } \\
\text { Texto produzido para expor } \\
\text { uma opinião e através da } \\
\text { utilização de argumentos busca } \\
\text { convencer o leitor; } \\
\text { Estabelece com o leitor uma } \\
\text { relação argumentativo- } \\
\text { persuasiva; } \\
\text { Dependendo do local de } \\
\text { publicação sua circulação pode } \\
\text { ser local, regional ou até } \\
\text { mundial (internet); } \\
\text { Busca, na maioria dos casos, } \\
\text { convencer ou não o leitor a } \\
\text { assistir ao filme. }\end{array}$ & $\begin{array}{l}\text { Selecionar os temas dizíveis do } \\
\text { gênero; } \\
\text { Adequar o texto: ao leitor e ao } \\
\text { suporte onde será publicado. }\end{array}$ \\
\hline $\begin{array}{l}\text { Capacidades de ação } \\
\text { requeridas no projeto } \\
\text { de comunicação escolar: } \\
\text { SITUAÇÃO DE } \\
\text { COMUNICAÇÃO E } \\
\text { REFERENTE TEMÁ- } \\
\text { TICO }\end{array}$ & $\begin{array}{l}\text { Texto escrito pelos alunos do } 9^{\circ} \\
\text { ano do ensino fundamental; } \\
\text { Texto produzido para expor } \\
\text { uma opinião e convencer o } \\
\text { leitor; } \\
\text { Estabelece com o leitor uma } \\
\text { elação argumentativo- } \\
\text { persuasiva; } \\
\text { Busca, na maioria dos casos, } \\
\text { convencer ou não o leitor a } \\
\text { assistir ao filme; } \\
\text { Em nossa proposta, publicado } \\
\text { no blog da escola; } \\
\text { Busca, na maioria dos casos, } \\
\text { convencer ou não o leitor a } \\
\text { assistir ao filme. }\end{array}$ & $\begin{array}{l}\text { Escrever uma resenha em } \\
\text { função do projeto de } \\
\text { comunicação proposto } \\
\text { na sequência didática. }\end{array}$ \\
\hline $\begin{array}{l}\text { Capacidades discursivas: } \\
\text { PLANIFICAÇÃO DO } \\
\text { TEXTO }\end{array}$ & $\begin{array}{l}\text { No primeiro parágrafo, } \\
\text { normalmente, aparecem } \\
\text { informações sobre o filme } \\
\text { resenhado como o nome do } \\
\text { filme, o diretor, o nome dos } \\
\text { atores ou atrizes principais, } \\
\text { até mesmo o resumo do filme; } \\
\text { O resumo pode ser feito ao } \\
\text { longo do texto seguido de } \\
\text { comentários do resenhista como } \\
\text { também em parágrafos }\end{array}$ & $\begin{array}{l}\text { Planejar o texto que contenha: } \\
\text { O contexto \Expansão do } \\
\text { contexto, ou seja, as } \\
\text { informações que vão além do } \\
\text { filme, podendo contar sobre } \\
\text { outros filmes já feitos pelos } \\
\text { atores e diretores, além de } \\
\text { relacionar o filme com outros } \\
\text { filmes. } \\
\text { Podendo ainda abordar sobre a } \\
\text { vida pessoal do elenco; }\end{array}$ \\
\hline
\end{tabular}




\begin{tabular}{|c|c|c|}
\hline & $\begin{array}{l}\text { específicos ou ainda isolado por } \\
\text { um subtítulo; } \\
\text { Ocorre a retomada nos } \\
\text { parágrafos seguintes de alguns } \\
\text { itens citados inicialmente para } \\
\text { tecer suas avaliações; } \\
\text { A avaliação do filme pode tanto } \\
\text { ser realizada ao longo do } \\
\text { desenvolvimento do texto por } \\
\text { meio da utilização de adjetivos } \\
\text { polidos e argumentos sólidos, } \\
\text { como também no final de forma } \\
\text { explícita (uso de verbos como } \\
\text { eu acho que, ou eu penso que, } \\
\text { etc.) ou implícita (sem o uso } \\
\text { desses verbos); } \\
\text { O discurso presente na resenha é } \\
\text { o teórico; } \\
\text { Escrito normalmente em terceira } \\
\text { pessoa; } \\
\text { Prevalece a presença do tempo } \\
\text { presente, com verbos } \\
\text { atemporais; } \\
\text { Aparecem sequências } \\
\text { descritivas, normalmente } \\
\text { quando o autor apresenta a obra; } \\
\text { sequências narrativas, } \\
\text { geralmente ao apresentar o } \\
\text { resumo do filme; } \\
\text { sequências explicativas também } \\
\text { aparecem quando o autor trata } \\
\text { do tema do filme; e sequências } \\
\text { argumentativas, que são muito } \\
\text { importantes, pois com elas o } \\
\text { autor tenta convencer ou não } \\
\text { seu leitor a apreciar o filme. }\end{array}$ & $\begin{array}{l}\text { As Informações básicas } \\
\text { referentes à parte técnica do } \\
\text { filme: nome, duração, elenco, } \\
\text { direção, roteiro, } \\
\text { gravadora, etc.; } \\
\text { Resumo contando o enredo do } \\
\text { filme no decorrer do texto, em } \\
\text { parágrafos específicos ou com } \\
\text { subtítulo; } \\
\text { A avaliação, ou seja, o } \\
\text { posicionamento expresso pelo } \\
\text { resenhista ao longo de seu texto. } \\
\text { Podendo as críticas serem } \\
\text { positivas ou negativas, } \\
\text { que acabam por recomendar, ou } \\
\text { não, o filme para o leitor; } \\
\text { Os argumentos, ou seja, as } \\
\text { justificativas referentes ao juízo } \\
\text { de valor (avaliação) proferido. } \\
\text { Em uma resenha } \\
\text { não é suficiente dizer que gosta } \\
\text { ou não gosta, é preciso justificar } \\
\text { a opinião com argumentos. }\end{array}$ \\
\hline $\begin{array}{l}\text { Capacidades linguístico- } \\
\text { discursivas: } \\
\text { TEXTUALIZAÇÃO }\end{array}$ & $\begin{array}{l}\text { A coesão nominal é feita através } \\
\text { de expressões nominais que se } \\
\text { referem tanto ao filme como a } \\
\text { seus elementos como os atores, } \\
\text { o diretor, os personagens, dentre } \\
\text { outros; } \\
\text { Uso de elementos de } \\
\text { referenciação, como as anáforas } \\
\text { nominais para evitar repetições } \\
\text { ao longo do texto; } \\
\text { Uso de conectivos que indicam } \\
\text { a adição de ideias como não } \\
\text { só...mas também, além disso, } \\
\text { ainda, etc.. } \\
\text { Uso de aspas para demonstrar a } \\
\text { presença de outras vozes além } \\
\text { da do resenhista; } \\
\text { Uso de verbos que traduzam as } \\
\text { ações dessas outras vozes como: } \\
\text { apresenta, sustenta que, fala } \\
\text { que, discute que, dentre outros. }\end{array}$ & $\begin{array}{l}\text { Utilizar os organizadores } \\
\text { textuais para marcar as } \\
\text { transições entre os tipos de } \\
\text { discurso e também para } \\
\text { relacionar as estruturas frasais. }\end{array}$ \\
\hline
\end{tabular}




\begin{tabular}{|l|l|l|}
\hline & $\begin{array}{l}\text { A avaliação pode ser realizada } \\
\text { através da utilização de } \\
\text { adjetivos, substantivos e } \\
\text { advérbios, além de se utilizar } \\
\text { uma linguagem "polida" que } \\
\text { atenuem possíveis afirmações } \\
\text { negativas sobre o filme } \\
\text { resenhado, podendo para isso: } \\
\text { utilizar expressões que atenuem } \\
\text { as opiniões como parece-me; } \\
\text { utilizar alguns tempos verbais } \\
\text { que também têm a função de } \\
\text { atenuar o que está sendo dito } \\
\text { como o futuro do pretérito. }\end{array}$ & \\
\hline DIMENSÃO TRANSVERSAL & $\begin{array}{l}\text { Ortografia } \\
\text { Pontuação } \\
\text { Paragrafação }\end{array}$ & $\begin{array}{l}\text { Escrever as palavras } \\
\text { corretamente; } \\
\text { Utilizar corretamente os sinais } \\
\text { de pontuação; } \\
\text { Organizar o texto em } \\
\text { parágrafos. }\end{array}$ \\
\hline
\end{tabular}

Fonte: Adaptado de Nascimento (2014)

Com a "desconstrução do gênero", ou seja, com a observação dos pontos mais comuns e relevantes do gênero, o professor tem uma ferramenta que o auxiliará em todo o processo de ensino da produção textual. Evidenciamos então que, para os discentes aprenderem um gênero textual de forma gradual, o trabalho com as sequências de atividades didáticas pode ser relevante, pois, desta forma, o professor pode ensinar a escrita, a leitura, a oralidade e os aspectos gramaticais de forma conjunta, o que faz mais sentido para quem aprende.

\section{Contexto de pesquisa}

Neste artigo, a SD apresentada é fruto de uma pesquisa-ação desenvolvida por uma professora em formação no Mestrado Profissional em Letras - ProfLetras, na Universidade Federal do Sul e Sudeste do Pará - UNIFESSPA. A pesquisa-ação, segundo Morin (2004), tem natureza social empírica e é responsável pela resolução de um problema coletivo. Nesse caso, o pesquisador deve participar de forma colaborativa, averiguando uma ação problemática que realmente careça de uma investigação.

O objetivo da pesquisa-ação é fazer a comparação de informações, avaliando e discutindo resultados e elaborando generalizações. Nesse tipo de pesquisa, os participantes não devem ser vistos como meras cobaias, mas devem desempenhar papel ativo. Nesse sentido, o importante não é somente adquirir conhecimentos sobre a questão, mas obter experiências capazes de contribuir para a discussão do problema ou avançar o debate. 
Ainda, segundo Morin (2004, p. 56), a pesquisa-ação permite aos atores a construção de teorias e estratégias que emergem do campo e que, em seguida, são validadas, confrontadas, desafiadas dentro do campo e acarretam mudanças desejáveis para resolver ou questionar melhor uma problemática. A professora participante desta pesquisa buscou, por intermédio da $\mathrm{SD}$, meios para que, em sua prática de sala de aula, os alunos pudessem alcançar melhores resultados na (re) escrita do gênero resenha.

O desenvolvimento da SD teve a participação de 37 alunos de uma turma do $9^{\circ}$ ano do Ensino Fundamental, no Sul do Pará. Para a realização da atividade, foram utilizadas 18 aulas com tempo reduzido ${ }^{3}$.

O gênero escolhido para ser didatizado foi a resenha de filme, pois o mesmo é pouco trabalhado no Ensino Fundamental e apresenta duas características importantes para o desenvolvimento da competência linguística dos alunos, que é resumir e tecer comentários a respeito de um determinado objeto.

Como já mencionado anteriormente, a SD tem como principal finalidade ajudar o aluno a dominar melhor um gênero de texto, permitindo-lhe falar ou escrever adequadamente nas diversas situações interativas. Nesse sentido, na próxima seção apresentamos um relato reflexivo a respeito da aplicação da SD desenvolvida pela professora participante desta pesquisa.

\section{Resenha de filme na sala de aula}

Inicialmente, vale destacar que, para a elaboração da SD, não foi feita uma modelização do gênero a ser ensinado. Isso pode ter dificultado o trabalho da professora, pois é através da modelização que o educador pode observar os componentes ensináveis do gênero para a elaboração das atividades a serem desenvolvidas na SD. A modelização do gênero também auxilia o docente na elaboração da lista de constatações e na correção inicial dos textos produzidos pelos alunos. Com isso, o professor pode verificar, com mais detalhes, o que os estudantes já sabem e o que precisam aprender sobre o gênero abordado.

\footnotetext{
${ }^{3}$ Durante o período de aplicação da SD, a escola estava se preparando para a festa junina que acontece anualmente. Assim, durante este período, para que os alunos ensaiassem a tradicional quadrilha junina, foi feito um horário de aula específico com uma redução de todas as aulas para 35 minutos cada.
} 
Como a professora não realizou a modelização do gênero, a SD aplicada foi construída a partir de saberes empíricos da docente sobre a resenha, além de alguns conhecimentos teóricos sobre a sequência didática. No Quadro abaixo, podemos observar o resumo da SD aplicada.

\begin{tabular}{|c|c|}
\hline \multicolumn{2}{|c|}{ Sequência didática } \\
\hline \multicolumn{2}{|c|}{$9^{\circ}$ ano do ensino fundamental } \\
\hline \multicolumn{2}{|c|}{ Produção de texto: Resenha de filme } \\
\hline \multicolumn{2}{|c|}{$\begin{array}{l}\text { Objetivos: } \\
\text { Ler, ouvir, interpretar e produzir resenhas de filme; } \\
\text { Conhecer o modo de organização do gênero textual resenha de filme; } \\
\text { Observar o uso de estratégias textuais e discursivas das resenhas de filme; } \\
\text { Identificar os usos sociais das resenhas; } \\
\text { Identificar estratégias argumentativas utilizadas nas resenhas; } \\
\text { Ampliar as possibilidades de produção de textos coerentes. }\end{array}$} \\
\hline \multicolumn{2}{|c|}{$\begin{array}{l}\text { Tempo estimado: } \\
9 \text { encontros (cada encontro corresponde a duas aulas) }\end{array}$} \\
\hline \multicolumn{2}{|c|}{$\begin{array}{l}\text { Situação comunicativa pretendida: } \\
\text { Produção de uma resenha do filme: "Os vingadores: era de Ultron”, para ser publicado } \\
\text { no blog da escola. }\end{array}$} \\
\hline \multicolumn{2}{|c|}{ Desenvolvimento } \\
\hline \multicolumn{2}{|c|}{ Apresentação da situação } \\
\hline $1^{\circ}$ Encontro & $\begin{array}{l}\text { Apresentar a proposta de produção de texto } \\
\text { para os alunos } \\
\text { deixando claro que no final das atividades } \\
\text { (sequência) eles, individualmente, } \\
\text { produzirão uma resenha de filme que será } \\
\text { divulgada } \\
\text { no blog da escola. }\end{array}$ \\
\hline $2^{\circ}$ Encontro & $\begin{array}{l}\text { Fazer com os alunos um levantamento dos } \\
\text { conhecimentos prévios que eles possuem } \\
\text { acerca do gênero a ser trabalhado. }\end{array}$ \\
\hline $3^{\circ}$ Encontro & $\begin{array}{l}\text { Realizar leituras (individuais, realizadas pelo } \\
\text { professor, realizadas pelos alunos) de } \\
\text { resenhas de filmes discutindo com os } \\
\text { alunos alguns aspectos relevantes na } \\
\text { estrutura de uma resenha, diferenciando } \\
\text { resenha de resumo. }\end{array}$ \\
\hline $4^{\circ}$ Encontro & $\begin{array}{l}\text { Realizar com os alunos um estudo sobre as } \\
\text { características e a estrutura de uma resenha. }\end{array}$ \\
\hline \multicolumn{2}{|c|}{ A primeira Produção } \\
\hline $5^{\circ}$ Encontro & $\begin{array}{l}\text { Assistir ao filme "Vingadores: Era de } \\
\text { Ultron" com os alunos, } \\
\text { solicitando que façam anotações sobre partes } \\
\text { do filme que acharem } \\
\text { importantes. }\end{array}$ \\
\hline
\end{tabular}




\begin{tabular}{|l|l|}
\hline $6^{\circ}$ Encontro & $\begin{array}{l}\text { Apresentar para os alunos um resumo do } \\
\text { filme assistido; } \\
\text { Apresentar para os alunos a ficha técnica do } \\
\text { filme escolhido para } \\
\text { ser resenhado; } \\
\text { Solicitar que os alunos escrevam uma } \\
\text { resenha do filme assistido; }\end{array}$ \\
\hline Módulos & \\
\hline Módulo I & $\begin{array}{l}\text { Realizar com os alunos uma análise } \\
\text { detalhada das partes que estruturam } \\
\text { uma resenha de filme (resumo, comentário e } \\
\text { avaliação). }\end{array}$ \\
\hline $7^{\circ}$ Encontro & \\
\hline Módulo II & $\begin{array}{l}\text { Realizar um estudo sobre coerência e coesão } \\
\text { textual dependendo } \\
\text { das dificuldades apresentadas pelos alunos. } \\
\text { Analisando os } \\
\text { textos levados para leitura, e os próprios } \\
\text { textos que os alunos } \\
\text { produziram. }\end{array}$ \\
\hline $8^{\circ}$ Encontro & \\
\hline $9^{\circ}$ Encontro & $\begin{array}{l}\text { Produção final da resenha de filme. } \\
\text { (Reescrita da resenha inicial) }\end{array}$ \\
\hline
\end{tabular}

Verificamos que a SD aplicada foi baseada na proposta de Schneuwly e Dolz (2004). $\mathrm{Na}$ apresentação da situação, percebemos que foi dito aos alunos o propósito interativo da produção de texto, conforme podemos observar no Exemplo 1:

\section{Exemplo 1}

Neste primeiro encontro, foi apresentada aos alunos a proposta de produção de texto, expliquei para os alunos como seria o processo de produção, ou seja, que eles provavelmente teriam que reescrever seus textos, pois muitas vezes os textos precisam de alguns ajustes que só vão sendo percebidos à medida que os lemos mais de uma vez. Disse que eles iriam produzir uma resenha de filme que no final das atividades seria publicada no blog da escola.

Observamos uma preocupação da professora em enfatizar que os alunos teriam que reescrever seus textos. Notamos também que esta foi a primeira informação dada a eles. Provavelmente, ela não pratica a reescrita com os alunos ou acredita que eles não tenham essa 
prática. Devemos também lembrar que a professora estava em uma turma cedida para o desenvolvimento da SD.

$\mathrm{Na}$ apresentação da situação, o professor deve deixar claro para os alunos todos os aspectos referentes às capacidades de ação. Para isso, o docente deverá mobilizar representações do contexto físico (lugar e o momento de produção, se tem ou não a presença de interlocutores), do contexto sociossubjetivo (qual é o papel social dos participantes, o objetivo da produção), além de ir mobilizando nos alunos os conteúdos estocados na memória sobre o gênero. Segundo Schneuwly e Dolz (2004), são as capacidades de ação que permitirão aos discentes adaptarem-se às características do contexto e do referente.

A apresentação da situação é uma etapa importante da SD, pois nela devem ser fornecidas aos alunos todas as informações necessárias para que conheçam o projeto de comunicação visado. E, de acordo com o Exemplo 2, isso pode ser identificado no trabalho da professora.

Exemplo 2

Fui conversando com os alunos e lhes perguntando se eles já haviam lido alguma resenha [...] tentei elencar deles suposições do que seria uma resenha [...] Fui escrevendo no quadro as características que eles foram falando e pedi que eles escrevessem no caderno para que depois confirmássemos ou não aquelas características [...] entreguei a cada aluno uma coletânea de seis resenhas de filme, sugeri que iniciássemos a leitura pela resenha do filme "Lisbela e o prisioneiro" $[\ldots]$

Assim que a leitura foi concluída passamos a discutir novamente sobre as características do gênero resenha. Perguntei a eles se as características que eles tinham elencado estavam presentes no texto lido [...] pedi para que eles me dissessem o que mais eles tinham observado como elementos importantes que deveriam estar presentes neste gênero [...] junto com eles li trechos da resenha que traziam opiniões do resenhista sobre o filme, buscando mostrar para eles que esse gênero trazia também a opinião do resenhista sobre o filme resenhado.

Observamos que houve uma preocupação da professora em não dar todas as informações prontas para os alunos, e que estes puderam ter contato com vários exemplares do gênero selecionado para ser estudado através de momentos de leituras da coletânea entregue a eles. Isso é notado na descrição da aula, conforme o Exemplo 3.

Exemplo 3

Ao iniciar a aula solicitei aos alunos que retomássemos as leituras das resenhas de filme [...] indaguei-lhes se as resenhas sempre deviam falar bem dos filmes [...] Para responder a essa 
pergunta disse a eles que iríamos ler a resenha do filme "Meu passado me condena: o filme". $[\ldots]$

Tentei demonstrar aos alunos que as resenhas de filme nem sempre recomendam aos leitores a apreciação do mesmo. Informei lhes que a opinião do resenhista é muito importante, pois pode contribuir ou não para que um filme seja aceito pelo público em geral. Além disso, pedi aos alunos que identificassem trechos da resenha que traziam um resumo da história contada no filme. Nesta aula de forma oral tentei demonstrar para os alunos que o resumo e a resenha são gêneros textuais diferentes. [...]

Iniciamos então uma leitura bem pausada das partes da resenha, onde fui demonstrando para os alunos alguns elementos essenciais que uma resenha deve conter (contexto/expansão do contexto, informações básicas, resumo, juízo de valor e argumento). Ao final da leitura relacionei para os discentes no quadro esses elementos, para que eles copiassem no caderno.

Conforme mencionado anteriormente, a SD aplicada foi construída a partir de conhecimentos empíricos sobre o gênero, uma vez que não foi construído o modelo didático do mesmo. Segundo Schneuwly e Dolz (2004), é através da elaboração do modelo didático que o professor observa o conjunto de recursos que podem ser transformados em conteúdos potenciais para o ensino do gênero escolhido e que serão mobilizados nas atividades escolares. E, por possibilitar várias realizações, podemos considerá-lo como uma base de dados para a construção do conjunto de sequências didáticas. No entanto, apesar de não ter construído o modelo didático do gênero, a professora seguiu as orientações dos referidos autores em relação à primeira etapa da SD.

No início da SD, poucos foram os momentos em que os alunos tiveram contato com atividades escritas, ou seja, as aulas aconteceram basicamente a partir de reflexões orais, como podemos perceber nos Exemplos 1, 2 e 3.

Vale ressaltar que o professor precisa conhecer bem o gênero a ser didatizado, pois o docente não deve frisar somente as questões superficiais e estruturais do gênero, mas também as de ordem discursiva. De acordo com o Exemplo 4, no intuito de alcançar esse objetivo, a professora elaborou, em conjunto com os alunos, uma lista de constatações que serviu de norteadora para a (re) escrita da resenha.

Exemplo 4: Lista de constatações para o gênero resenha de filme

- Sua resenha tem título?

- Seu texto traz as informações básicas do filme, ou seja, refere-se à parte técnica do filme: nome, duração, elenco, direção, roteiro, gravadora, entre outros?

- Seu texto traz o contexto do filme e a expansão do contexto? Traz informações que vão além do filme? Conta sobre outros filmes e aborda a vida do elenco?

- Sua resenha traz a descrição resumida (enredo) do filme? 
- Seu texto tem juízo de valor, ou seja, traz sua opinião, o seus posicionamentos expressos ao longo de seu desenvolvimento? Traz uma crítica positiva ou negativa? Recomenda, ou não, o filme para o leitor?

- Você utilizou argumentos consistentes e convincentes para justificar seu juízo de valor?

- Seu texto (resenha) apresenta desvios de gramática e de coerência?

Fonte: Professora participante da pesquisa

A partir do Exemplo 4, além dos pontos apresentados, a professora poderia ter acrescentado à lista tópicos relacionados aos elementos de referenciação e ao uso dos conectivos. Mesmo assim, constatamos que a lista elaborada contempla as três capacidades de linguagem: capacidade de ação; capacidade discursiva; e capacidade linguístico-discursiva (BRONCKART, 2007). Para que os alunos produzissem seu primeiro texto, a professora os levou para o cinema da cidade, a fim de que assistissem ao filme sobre o qual escreveriam a resenha, conforme observamos no Exemplo 5.

\section{Exemplo 5}

Neste dia cheguei à escola e os alunos do $9^{\circ}$ ano "A" estavam eufóricos. Deu um pouco de trabalho para organizar tudo para levá-los ao cinema da cidade, mas no final deu tudo certo.[...] De forma geral tudo ocorreu bem, os alunos gostaram muito

de sair do ambiente escolar para assistir ao filme.

Como podemos perceber no Exemplo 5, os alunos gostaram de sair do ambiente escolar para assistir ao filme, fato que também contribuiu para os estudantes identificarem aspectos sociais relacionados ao gênero abordado. Nas aulas seguintes, antes de solicitar que escrevessem a primeira versão da resenha, a professora leu para eles um resumo do longametragem e disponibilizou uma ficha técnica do mesmo para facilitar a produção de texto.

A produção inicial teve o objetivo de servir como um diagnóstico, já que, por meio dela, a professora pôde averiguar em quais aspectos os alunos se saíram bem e em quais precisavam melhorar. Por isso, na correção dos textos, foi observado, com base na lista apresentada no Exemplo 4, se os alunos apresentaram um resumo da obra e se emitiram juízo de valor no intuito de conquistar a adesão dos leitores da resenha. Além disso, foram observados os pontos referentes à escrita padrão, como concordância, pontuação, paragrafação etc. Após isso, a docente iniciou a elaboração dos módulos.

Schneuwly e Dolz (2004) destacam que o princípio essencial para a elaboração dos módulos é o de variar os modos de trabalho. Para isso, o professor deve utilizar um arsenal bastante diversificado de atividades e de exercícios. Assim, o professor possibilita que os alunos 
tenham acesso aos instrumentos e às noções por vias diferentes, o que aumenta as suas chances de ter sucesso. Por isso, em conformidade com os referidos autores, percebemos que, durante a aplicação dos módulos, as aulas foram pautadas em reflexões orais e em atividades escritas, no intuito de contribuir com o desenvolvimento das capacidades de linguagem dos alunos.

Assim, com o objetivo de fazer os alunos compreenderem como os conectivos são importantes para estabelecer a relação entre as partes e, consequentemente, entre os sentidos do texto, a docente propôs atividades, como a que apresentamos no Exemplo 6, adaptada de um manual didático.

\section{Exemplo 6}

01. Nas questões seguintes, apresentamos alguns segmentos de discurso separados por ponto final. Retire o ponto final e estabeleça entre eles o tipo de relação indicado entre parênteses, usando para isso os elementos de coesão adequados e fazendo as alterações necessárias.

a) $\mathrm{O}$ homem alcançará a satisfação de suas necessidades. $\mathrm{O}$ homem viver em sociedade. (condição)

b) Os seres humanos vivem em sociedade. Eles necessitam de apoio material, espiritual e psicológico. (causa)

c) A sociedade deve ser organizada com justiça. Todas as pessoas possam satisfazer suas necessidades. (finalidade)

d) Uma pessoa poderia ter condições materiais para viver isolada. Ela poderia sentir falta de companhia. (oposição)

02. Na frase: Sou coletivo. Tenho o mundo dentro de mim. O elemento

coesivo que melhor uniria estas duas orações é:
a) $\mathrm{E}$
b) Afinal
c) Entretanto
d) $\mathrm{Ou}$
e) Ainda que

A professora também poderia ter elaborado outras atividades a partir das resenhas selecionadas para as leituras durante a apresentação inicial da SD. Notamos aqui a dificuldade que muitos professores possuem de se distanciar do manual didático. Muitas vezes, isso acontece por conta do comodismo de já querer encontrar as atividades prontas. Em outros casos, isso se deve porque, realmente, os professores não têm acesso a outros recursos didáticos capazes de auxiliá-los no dia a dia de sala de aula.

Outro ponto que merece ponderação sobre a SD aplicada diz respeito à produção final dos estudantes, como é observado no Exemplo 7. 
Exemplo 7

Num primeiro momento devolvi-lhes os textos que eles haviam me entregado. Eles estranharam que não houvesse nada riscado nas folhas entregues. Expliquei-lhes que eu não poderia riscá-las porque as utilizaria depois na minha pesquisa. E de forma geral expliquei o que eu queria que eles observassem nos textos para refazerem. Pedi-lhes que olhassem as anotações no caderno e seguissem a "lista de constatações" para que reescrevessem seus textos.

A docente não grafou nos textos dos alunos o que foi observado na primeira produção. A correção ocorreu dessa forma para que os alunos, de posse da lista de constatações, pudessem, em conjunto com a professora, averiguar os pontos positivos e negativos em relação à primeira escrita da resenha. Melhor dizendo, houve uma correção coletiva, pois, assim, todos puderam, conjuntamente, fazer questionamentos e tirar as dúvidas. Essa estratégia da professora condiz com uma atividade epilinguística (GERALDI, 2003), já que os alunos puderam adequar a própria escrita de acordo com as especificidades do gênero abordado.

Os alunos também tiveram dificuldades para realizar a reescrita, por isso, a professora precisou ir orientando-os, de forma individual, mostrando-lhes o que podiam melhorar nos textos.

Seria interessante que a professora tivesse feito, também, anotações indicativas para o aluno observar melhor sua escrita e, assim, adequar o gênero à proposta de interação. Para isso, não necessitaria "riscar" os textos dos alunos, poderia ter feito essas anotações em uma ficha avaliativa que ela mesma poderia ter montado, com base na lista de constatações.

Constatamos que, apesar das dificuldades enfrentadas pela professora ao longo do trabalho, como a redução dos horários e a falta de material de apoio, a SD, conforme aplicada, buscou contribuir para o desenvolvimento das capacidades de linguagem dos alunos a respeito do gênero resenha. Mesmo assim, compreendemos que os aspectos abordados sobre o gênero, nos módulos, poderiam ter contemplado as modalizações, o processo de referenciação e a inserção das vozes no texto. Faltou também um planejamento mais criterioso da SD, como a elaboração do modelo didático.

\section{Considerações finais}

Neste artigo, ao fazer a comparação entre o que é teorizado a respeito da SD e a atividade de produção textual realizada pela professora participante da pesquisa, observamos que o ensino, organizado em sequências de atividades didáticas, pode contribuir para a prática docente, uma vez que a professora foi capaz de elaborar e aplicar a SD, com o intuito de auxiliar os alunos na escrita do texto. Mesmo assim, compreendemos que a docente poderia ter 
desenvolvido outras atividades nos módulos capazes de ampliar o conhecimento dos estudantes com relação às capacidades de linguagem referentes à resenha. Assim, poderia ter explorado as sequências textuais, a inserção das vozes no texto e o processo de referenciação.

Constatamos também que planejar o ensino de Língua Portuguesa, seguindo as diretrizes dos PCNLP (BRASIL, 1998), requer compreender a língua como um articulador das relações cotidianas com outros falantes e seu ensino. Como já destacado anteriormente, deve proporcionar aos alunos situações reais (social) de interação, as quais só acontecem mediadas por um gênero textual. Notamos que a professora, ao elaborar a SD para a pesquisa, teve a preocupação de adequar sua proposta seguindo os PCNLP (BRASIL, 1998), pois a atividade sequenciada traz uma situação de comunicação social real, que é a veiculação dos textos no blog e no mural da escola.

Aferimos, durante a análise, que a professora não realizou a modelização do gênero, fato que pode ter dificultado seu trabalho na elaboração e aplicação dos módulos. Por isso, destacamos a importância da modelização do gênero, já que pode guiar o processo de construção e aplicação de uma SD. Como já frisado, é através da elaboração do modelo didático que o professor identifica os elementos que podem ser transformados em conteúdos potenciais para o ensino do gênero didatizado e que serão mobilizados nas atividades escolares. Na SD aplicada, resumir o filme, emitir juízos de valor, utilizar as modalizações adequadas e estabelecer corretamente o processo de referenciação são alguns exemplos do que poderia ser transformado em conteúdo potencial para o ensino do gênero resenha.

Cabe destacar ainda que, na SD desenvolvida, as capacidades de ação foram contempladas, pois os alunos conseguiram produzir textos adequados à situação de interação, com a intenção de conquistar a adesão dos leitores em relação ao filme. No entanto, faltou ainda apresentar mais atividades nos módulos que contribuíssem para o desenvolvimento das capacidades discursivas e linguístico-discursivas dos alunos, como explorar os mecanismos de conexão, trabalhar os modos de expressão da subjetividade do resenhista e abordar a organização das sequências textuais mais comuns à resenha. Assim, apesar de não apresentar estratégias de ensino que vão totalmente ao encontro das orientações teóricas sobre o ensino dos gêneros textuais, a professora, de acordo com os saberes já construídos, viabilizou a inserção dos gêneros textuais no contexto escolar.

\section{Referências}


ANTUNES, Irandé. Muito além da gramática: por um ensino de línguas sem pedras no caminho. São Paulo: Parábola, 2007.

BRASI L. Ministério da Educação e do Desporto. Secretaria de Educação Fundamental. Parâmetros curriculares nacionais terceiro e quarto ciclos do ensino fundamental: Língua Portuguesa. Brasília, DF: MEC/SEF, 2001.

Ministério da Educação e do Desporto. Secretaria de Educação Fundamental. Parâmetros curriculares nacionais terceiro e quarto ciclos do ensino fundamental: Língua Portuguesa. Brasília, DF: MEC/SEF, 1998.

BRONCKART, J-P. Atividade de Linguagem, Textos e Discursos: por um interacionismo sociodiscursivo. São Paulo: EDUC, 2007.

DOLZ, Joaquim [et. al.]. Produção escrita e dificuldades de aprendizagem. Campinas, SP: Mercado de Letras, 2010.

GERALDI, João Wanderley. Portos de passagem. São Paulo: Martins Fontes, 2003.

MACHADO, Anna Rachel. A perspectiva interacionista sociodiscursiva de Bronckart. In: MEURER, J. L. [et al.] Gêneros, teorias, métodos e debates. São Paulo: Parábola Editorial, 2005.

MACHADO, Anna Rachel; CRIS TOVÃO, Vera Lúcia. A construção de modelos didáticos de Gêneros: aportes e questionamentos para o ensino de gêneros. Linguagem em (Dis)curso LemD, Tubarão, v. 6, n. 3, p. 547-573, 2006.

MARCUSCHI, Luiz Antônio. Linguística do texto: o que é e como se faz? São Paulo: Parábola Editorial, 2012.

Gêneros textuais: definição e funcionalidade. In DIO NIZIO ,Angela Paiva [et. al] Gêneros textuais e ensino. São Paulo: Parábola, 2010.

MORI N, A. Pesquisa-ação integral e sistêmica: uma antropedagogia renovada. Trad. de Michel Thiollent. Rio de Janeiro: DP \& A, 2004.

NASCIMENTO, E. L. (Org.). Gêneros Textuais - Da didática das línguas aos objetos de ensino. Campinas-SP: Pontes, 2014.

SCHNEUWLY, Bernard; DOLZ, Joaquim. Gêneros orais e escritos na escola. Tradução e organização Roxane Rojo e Glaís Sales. Campinas- SP: Mercado de Letras, 2004. 